\title{
Scientific freedom and responsibility in a biosecurity context
}

\author{
Catherine Rhodes
}

Scientific freedoms are exercised within the context of certain responsibilities, which in some cases justify constraints on those freedoms. (Constraints that may be internally established within scientific communities and/or externally enacted.) Biosecurity dimensions of work involving pathogens are one such case and raise complex challenges for science and policy. The central issues and debates are illustrated well in the development of responses to publication of ('gain of function') research involving highly pathogenic avian influenza, by a number of actors, including scientists, journal editors, scientific academies, and national and international policy groups.

The core tension that can arise between working to protect health by promoting work on pathogens (to support surveillance and response efforts) and working to protect health by setting limits to work on pathogens that poses risks to health through accidental or deliberate releases, is reflected in and has been responded to by international (and some national) policy processes. These responses have placed increasing emphasis on the responsibilities of scientists. Framed within recognition of the reciprocal responsibilities of scientists and policymakers, further joint work is needed to manage this tension and develop appropriate and effective international responses.

\section{Scientific freedoms and (scientific) responsibilities}

Scientific freedom is subject to internal and external constraints, some of which relate to responsibilities that are widely recognised by the scientific community. This chapter focuses on international dimensions of sciencepolicy interactions, and the conception of the scientific community used in this chapter reflects this, and fits the definition provided by Henk Verhoog (1981: 583): 'the community of scientific workers wherever they are in the world, sharing the same general conception of nature and the same basic methodological norms'. The responsibilities discussed in this chapter may be assigned to individual scientists, to groups working in particular areas, and/or to the scientific community as a whole. 


\section{Broadening of scientific responsibilities}

Scientific responsibility has both internal and external dimensions. The internal dimensions can be thought of as the responsibilities that scientists have towards the scientific community and to upholding good scientific practice, and relate to traditional elements of 'responsible conduct of research'. Frankel and Carlson (2011), for example, list the following areas covering the main elements of internal scientific responsibilities:

- data acquisition, management, sharing and ownership;

- conflict of interest and commitment;

- human subjects;

- animal welfare;

- research misconduct;

- publication practices and responsible authorship;

- mentor/trainee responsibilities;

- peer review; and

- collaborative science.

The more traditional conception of scientific responsibility has broadened to include external dimensions - because of the important relationship that science has with and the implications it has for society - and in line with recognition of the increasingly global nature of science (National Academies 2009; Rhodes and Sulston 2010; InterAcademy Council 2012). These more outward-facing responsibilities include consideration of research outcomes and alignment of research goals and plans with societal concerns. The German Ethics Council (2014: 57) makes similar arguments, for example stating that:

[T] he sciences are increasingly understood as being not merely self-contained processes that take place within a scientific community, but rather as being an integral component of general societal interrelationships . . Accordingly, the ethical appraisal of science must concern itself not only with the practical consequences of knowledge, but also with the effects of the research process and its findings on society.

Biosecurity concerns relate to the dual-use nature of some research, and this appears primarily to relate to the external dimension of scientific responsibility - relating to avoidance of harm to society through the deliberate misuse of research 'to pose a threat to public health and safety, agricultural crops and other plants, animals, the environment or materiel' (NSABB n.d.). Making clear the connection of biosecurity concerns to internal norms of responsible conduct is also important, and modifications to e.g. laboratory practices may be necessary (WHO 2013).

Some of the publications providing guidance on responsible conduct of research have incorporated certain aspects of biosecurity into internal responsibilities. For example, the InterAcademy Council's 2012 Report 
- Responsible Conduct in the Global Research Enterprise, includes 'misuse of biological agents' within its list of irresponsible research practices (5).

In recent years some countries, for example the Netherlands and Germany have produced more specific guidance on scientific responsibility and biosecurity (Royal Netherlands Academy of Arts and Sciences 2013; German Ethics Council 2014). However, such activities are not widespread, and it is unclear whether the scientific community has a high level of awareness of such guidance and what it might mean in practice, nor how broadly such responsibilities are accepted as an extension of internal norms in the scientific community.

Appropriate handling of biosecurity will also help to ensure that public trust in science is not jeopardised - which is an important general motivation for upholding standards of responsible scientific conduct. This is clearly stated in the World Health Organization's Laboratory Biosecurity Guidance (2006: 2, 25)

The general public expects laboratory personnel to act responsibly and not to expose the community to biorisks, to follow safe working practices (biosafety) associated with practices that will help keep their work and materials safe and secure (biosecurity).

Effective laboratory biosecurity is a societal value that underwrites public confidence in biological science.

This was also a motivation for the Biotechnology and Biological Sciences Research Council (BBSRC), Medical Research Council (MRC) and Wellcome Trust's Position Statement on Dual Use Research of Concern and Research Misuse (2015: para. 22).

Biosecurity responsibilities relate not only to ensuring that individuals do not follow intentionally harmful/prohibited lines of research, but also to consideration of how research might be used by others, with a requirement in certain cases to modify research plans or communication activities, and even to forgo certain lines of research altogether, when there is a significant risk of misuse. It is generally agreed that this will only apply to a very small subset of research (Royal Society 2012: 57; DFG and Leopoldina 2014: 10; BBSRC et al. 2015: para. 9; NSABB 2016: 1).

Guidance documents and statements produced by scientific academies and funding bodies relating to scientific responsibility place strong emphasis on the fundamental importance of openly communicating research - to contribute to scientific progress, to enable replication and verification of findings, etc. Connected to this, the ability to openly communicate is viewed as a core scientific freedom. The importance of this aspect of scientific freedom and responsibility is particularly significant in terms of the discussion in this chapter. Among many examples of such statements:

Open communication and deliberation sit at the heart of scientific practice.

(Royal Society 2012: 13) 
$[\mathrm{P}]$ ublication in a peer-reviewed journal is the most important way of disseminating a complete set of research results. (National Academies 2009: 29)

Researchers who fail to meet these expectations place their reputations at risk. (InterAcademy Council 2012: 16)

The free exchange of information and especially the publication of results are important factors for scientific knowledge and scientific progress. (DFG and Leopoldina 2014: 13)

Some more recent documents have qualified this expectation slightly (Royal Society 2012; DFG and Leopoldina 2014), but it is not clear whether this is a generally accepted modification to the core scientific norm of open communication - and it is not clear how this should be balanced with apparently contradictory statements. The following statements, for example, appear in the Royal Society's Science as an Open Enterprise report (2012: 9, 57):

Qualified openness

Opening up scientific data is not an unqualified good. There are legitimate boundaries of openness which must be maintained in order to protect commercial value, privacy, safety and security. Careful scrutiny of the boundaries of openness is important where research could in principle be misused to threaten security, public safety or health.

A joint report by the Royal Society, the InterAcademy Panel and the International Council of Science in 2006 concluded that 'restricting the free flow of information about new scientific and technological advances is highly unlikely to prevent potential misuse and might even encourage misuse'.

\section{Reciprocal responsibilities of science and society}

In general, the relationship between science and society can be described as reciprocal, and there are responsibilities for both sides that are associated with this. Scientists have responsibilities towards society inter alia because science contributes to a range of social goods, because it has significant social and economic impacts, and because it is ultimately funded by society, whether through taxation or consumer spending (iSEI 2010: 3; InterAcademy Council 2012: v). These responsibilities include: addressing the concerns, values and interests of society; consideration of the implications of their work for society; providing policy advice in areas in which they are qualified to do so; and accepting some limitations on scientific freedom or conditions on practice to align with social goals and values.

Society as a collective recipient of benefits from scientific research, has responsibilities towards it, for example in facilitating scientific progress through e.g. funding, provision of education and training, and enabling dialogue and scrutiny (e.g. through broad scientific literacy), and by generally protecting scientific freedoms where these don't substantially conflict with other protected values. In other words, 'society needs to provide 
just and effective conditions for the increase of scientific knowledge' (iSEI 2010: 3).

Policymakers are important intermediaries in the reciprocal relationship between science and society. They need to respond to and where necessary achieve balance between the interests and values of both groups - utilising a range of policy tools (e.g. regulation, licensing, guidance, funding). Scientists often have specialist expertise that can inform policymaking, and should seek to provide appropriate input (InterAcademy Council 2012: 28). Policymakers have a responsibility to ensure that evidence/advice is sought and to consider the impacts of policy for scientific practice. This will, however, be in the context of a variety of constraints and demands on policymaking, and limitations on policymakers' freedom need to be acknowledged, in order to establish realistic expectations of science-policy relationships. This point is picked up on in the World Health Organization's guidance Responsible Life Sciences Research: 'One the one hand, government policy should aim to promote the advancement of science. Scientific progress usually has important societal (including economic) benefits; and promoting the good of society is a primary responsibility of government ... At the same time, safety, security and economic development are significant responsibilities of governments' (WHO 2010: 28).

\section{Tension between freedoms and responsibilities}

There are many different situations in which freedoms and responsibilities may be in tension and need to be carefully balanced. In the biosecurity context a core tension arises because some research which aims to protect health can also create health risks, particularly research involving work on dangerous pathogens. Such research serves to protect health (e.g. by supporting preparedness and surveillance efforts, the development of treatments, and other public health responses to outbreaks). Through unintentional or deliberate actions such work can also threaten health e.g. through accidental release of a pathogen, or through deliberate misuse e.g. to create weapons. It is the latter - deliberate misuse (of materials and data and knowledge emerging from research) that is a central concern in biosecurity, and the main focus of discussion in this chapter.

Scientific advances tend to contribute to both aspects of this tension, because they can serve both to facilitate misuse (e.g. by enabling creation of more desirable warfare agents, such as pathogens that are more virulent, environmentally stable, or for which there are no prophylactic measures available), and to enhance defence measures (e.g. through new detection tools), and assist identification and monitoring of, and response to outbreaks.

\section{The biosecurity context}

The term biosecurity has various meanings in different contexts. ${ }^{1}$ Its use in this chapter covers prevention of the deliberate misuse of biological 
(and related) sciences to cause harm. While most scientific work can have dual-use implications, ${ }^{2}$ certain types of research are viewed as presenting particularly significant biosecurity risks, and have been subject to particular policy attention. The types of research of concern are frequently linked in policy to research on particular agents (including those associated with past biological weapons programmes) and to particular types of experiment. This is the approach, for example, used in the US government's Policy for the Oversight of Dual Use Research of Concern (US Government 2012). A widely used example of types of 'experiments of concern' is found in the 2004 report Biotechnology Research in an Age of Terrorism (National Research Council of the National Academies 2004):

1. Would demonstrate how to render a vaccine ineffective.

2. Would confer resistance to therapeutically useful antibiotics or antiviral agents.

3. Would enhance the virulence of a pathogen or render a non-pathogen virulent.

4. Would increase the transmissibility of a pathogen.

5. Would alter the host range of a pathogen.

6. Would enable evasion of diagnostic/detection modalities.

7. Would enable the weaponisation of a biological agent or toxin.

Box 2 in Position Statement on Dual Use Research of Concern and Research Misuse (BBSRC et al. 2015: 2) suggests the addition of:

[E]xperiments that would: generate or reconstitute an eradicated or extinct agent or toxin.

[T] he development of new technologies or tools with genetic applications - such as in the areas of bio-processing or bio-fermentation scale-up which could, for example, make it easier to synthesise or produce harmful agents.

$[P]$ rojects that carry very little potential for misuse, but where the risk would be greatly increased by emerging data or methodologies from other disciplines, for example studies on a toxin that cannot be introduced easily into humans, but which might be deliverable by advances in materials science or aerosol physics.

\section{'Gain of function' research}

The way and the extent to which biosecurity considerations might limit research on pathogens has gained a high profile among some scientific, security and policymaking groups over the past few years, particularly because of debate around the publication of highly pathogenic avian influenza (H5N1) 'gain of function'3 experiments. 
Two groups - led by Ron Fouchier and Yoshihiro Kawaoka - had been conducting research to identify mutations to the H5N1 influenza virus that could make it transmissible between humans. The work aimed to assist in the identification of strains likely to cause pandemics and in the development of vaccines and treatments. The groups submitted manuscripts to Nature and Science in 2011. As the research had received US federal funding (through the National Institutes for Health), the National Science Advisory Board for Biosecurity (NSABB) reviewed the manuscripts before publication. The NSABB is an advisory committee for the US government, inter alia addressing 'policies governing publication, public communication, and dissemination of dual use research methodologies and results' (US Department of Health and Human Services 2016: 1).

In giving its recommendations on the original transcripts, the NSABB noted that the publications 'described the generation of mutations in $\mathrm{H} 5 \mathrm{~N} 1$ that enable the airborne transmission of the virus between ferrets'; 'recognized the importance of the research in advancing knowledge of influenza transmission and supporting public health efforts'; but noted that 'specific findings would enable others to synthesize and express a H5N1 strain with mammalto-mammal transmissibility' and that they had 'significant concerns that information in the manuscripts could be misused to endanger public health and national security'. They therefore recommended 'the information in these manuscripts be published in a redacted form with the omission of certain details that could enable the direct misuse of the research by those with malevolent intent' (2012: 1).

The NSABB reviewed revised versions of the manuscripts in March 2012, along with 'new non-public epidemiological information, and security information . . . presented in a classified briefing' (2012: 1). While it still viewed the manuscripts as presenting 'dual use research of concern', a majority concluded that:

As currently written, the revised manuscripts do not appear to provide information that would enable the near-term misuse of the research ... The mutations described in the manuscripts do not appear to result in H5N1 viruses that are both highly pathogenic and transmissible between ferrets through the air ... The revised manuscripts provided a greater appreciation of the direct applicability of the information to ongoing and future influenza surveillance efforts. (NSABB 2012: 2-3)

It recommended that 'the revised Kawaoka manuscript be communicated in full' and that - with some further revisions, the Fouchier manuscript could also be published (NSABB 2012: 5). The manuscripts were published in Nature and Science later in 2012.

Alongside this process, scientists working on these types of $\mathrm{H} 5 \mathrm{~N} 1$ influenza transmission studies held a voluntary moratorium, to give space for further discussion and debate. This lasted around one year; with the researchers 
announcing in early 2013 that its aims had largely been met and so research would continue (Fouchier et al. 2013).

There have been additional policy responses in the US, including advice issued in 2013 on enhanced biosafety requirements for research on highly pathogenic H5N1 viruses (US Department of Health and Human Services, National Institutes of Health 2013) and - announced in October 2014 - a research funding pause 'on selected gain of function research involving influenza, MERS and SARS viruses' during a deliberative process towards recommendations that would inform the development and adoption of a new US government policy governing the funding and conduct of gain-offunction research' (US Government 2014). This included public consultation, a risk-benefit analysis, and an ethical analysis of such research, contributing to recommendations from the NSABB. The recommendations were published in May 2016, and they advise subjecting 'a small subset of GOF research - GOF research of concern (GOFROC)' to additional review and oversight (NSABB 2016: 1).

\footnotetext{
Research proposals involving GOF research of concern entail significant potential risks and should receive an additional, multidisciplinary review, prior to determining whether they are acceptable for funding. If funded such projects should be subject to ongoing oversight at the federal and institutional levels. (NSABB 2016: 2)
}

The NSABB also outlined particular attributes of 'gain of function research of concern' and a set of principles to guide funding decisions (2016: 43-4).

There are a few other examples of additional guidance being provided in response to the influenza transmission studies, including the Royal Netherlands Academy of Arts and Sciences report Improving Biosecurity: Assessment of Dual Use Research (2013), and the German Ethics Council's opinion Biosecurity - Freedom and Responsibility of Research (2014). The World Health Organization (WHO) has hosted technical discussions on the Fouchier and Kawaoka studies (WHO 2012), and on dual-use research of concern more broadly (WHO 2013). A coordinated international approach to the funding, conduct, oversight and communication of such experiments - although recognised to be necessary given the global nature of the scientific enterprise and the public health threat - has yet to be developed.

\section{International governance}

There is a long-standing international recognition of the need to protect human, animal and plant life and health from transboundary disease threats. Within these efforts it is recognised that international scientific collaboration is essential for appropriate and effective monitoring, surveillance and response efforts (OIE 2015; WHO 2010). Biosecurity issues sit at the intersection 
of security and health and there are relevant international rules, organisations and other governance mechanisms in both domains, key components of which are outlined below.

\section{The Biological Weapons Convention}

The Biological Weapons Convention (BWC) is based around a core prohibition in Article I:

Each State Party to this Convention undertakes never in any circumstance to develop, produce, stockpile or otherwise acquire or retain:

(1) Microbial or other biological agents or toxins, whatever their origin or method of production, of types or in quantities that have no justification for prophylactic, protective or other peaceful purposes. (United Nations Biological Weapons Convention 1972)

Notably, the Convention does not seek to restrict use of biological agents and toxins for peaceful purposes; it explicitly encourages participation and international cooperation for such purposes, particularly including the prevention of disease:

(1) The States Parties to this Convention undertake to facilitate, and have the right to participate in, the fullest possible exchange of equipment, materials and scientific and technological information for the use of bacteriological (biological) agents and toxins for peaceful purposes. Parties to the Convention in a position to do so shall also cooperate in contributing individually or together with other States or international organisations to further development and application of scientific discoveries in the field of bacteriological (biological) for the prevention of disease, or for other peaceful purposes. (Article X)

States parties to the BWC track scientific and technological developments relevant to the Convention, including those 'that have potential for uses contrary to the provisions of the Convention' and those 'that have potential benefits for the Convention, including those of special relevance to disease surveillance, diagnosis and mitigation' (United Nations 2012: 23).

Other relevant governance efforts that fall within the security domain include work under United Nations Security Council Resolution 1540, which 'Obliges States, inter alia, to refrain from supporting by any means non-State actors from developing, acquiring, manufacturing, possessing, transporting, transferring or using nuclear, chemical or biological weapons and their delivery systems' (United Nations 1540 Committee, n.d.) and informal export control arrangements of the Australia Group (Government of Australia 2007). 


\section{Health and disease control efforts}

There are international rules and systems for the protection of human, animal and plant life and health. Those which seek to prevent the introduction and spread of infectious disease are particularly relevant, and include:

- The international organisations tasked with protection of human, animal and plant health - the World Health Organization, the World Animal Health Organization (OIE), and the Food and Agriculture Organization (FAO).

- The main rules seeking to control the movement of pests and diseases through international travel and trade routes (which also establish requirements e.g. for reporting and managing outbreaks of international concern) - the International Health Regulations, the Terrestrial and Aquatic Animal Health Codes and Manuals, and the International Plant Protection Convention.

- Specific guidance on laboratory biosafety and biosecurity, to minimise the risks of accidental or deliberate release of pathogens from laboratories and the risks to health of laboratory workers.

- Guidance on the transport of infectious substances (generally found within dangerous goods regulations issued separately for each transport mode, but with key parts summarised in WHO's Guidance on Regulations for the Safe Transport of Infectious Substances).

- A range of surveillance and response systems - including more general systems such as WHO's Global Outbreak Alert and Response Network and OIE's World Animal Health Information System; more specific systems such as WHO's Global Influenza Surveillance and Response System.

- Expert and laboratory networks including WHO's and OIE's collaborating centres and reference laboratories, and joint systems such as OFFLU, a collaboration of the OIE and FAO networks on animal influenzas.

The disease surveillance and response systems and collaborative networks, in particular, rely on timely and effective sharing of materials, data and research.

While these organisations primarily focus on natural disease threats, they recognise that their systems will play an essential role in the identification of and response to any deliberately caused disease outbreaks. The OIE, for example, addressed these issues within its Biological Threat Reduction Strategy: 'The same disease surveillance and intelligence systems that are in place to detect day-to-day occurrences of natural outbreaks in animals, within countries and at national borders, will also detect deliberate and accidental releases' (OIE 2015: 3).

\section{Handling the tension}

The tension between protecting health through access to pathogens and open communication of research results and protecting health by restricting 
access to pathogens and associated data and knowledge with misuse potential is being addressed within these organisations and by states parties to the BWC. In their responses to the misuse potential of work involving pathogens, in recent years they have placed increasing emphasis on the responsibilities of scientists. This includes recommendations about building awareness among scientific communities of their legal and moral obligations, development of codes of conduct and ethics education and training, and the creation of a culture of responsible science, in which scientists are able to make informed decisions about the biosecurity aspects of their research (which may in some cases constrain scientific freedoms e.g. by limiting or delaying communication of research, or not following certain lines of enquiry).

For example, the Seventh Review Conference of the BWC noted 'the value of national implementation measures' which 'implement voluntary management standards on biosafety and biosecurity'; 'promote the development of training and educational programs' and 'encourage the promotion of a culture of responsibility amongst relevant national professionals and the voluntary development, adoption and promulgation of codes of conduct' (United Nations 2012: art. IV, para. 13, secs. a, d and e). And its series of intersessional meetings from 2012 to 2015 included in the standing agenda item on review of scientific and technological developments, the topics of 'voluntary codes of conduct and other measures to encourage responsible conduct by scientists, academia and industry' and 'education and awareness raising about risks and benefits of life sciences and biotechnology' (2012: para. 22, secs. d and e).

The WHO's Laboratory Biosecurity Guidance included recommendations on development of codes of conduct for researchers and other laboratory staff, which ought to include: 'evaluation of the purpose of the work, consideration for its impact the publication of research results, and [enumeration of] considerations and conditions for or against the publication of results that may have dual-use implications' (2006: 21); and that there is a need for promotion of 'a culture of awareness, shared sense of responsibility, ethics and respect of codes of conduct within the international life sciences community' (2006: 30). The WHO further recommended that 'comprehensive bioethical reviews should be carried out and documented before final decisions are reached on the publication of data, balancing pros and cons of their dissemination' (2006: 21). (Interestingly it then went on to suggest that one particular area in which further examination of 'bioethical considerations, international review and control of this research' was needed was in studies 'with the highly pathogenic H5N1 to investigate virus transmissibility' (2006: 21).) (The WHO also produced a guidance document Responsible Life Sciences Research for Global Health Security in 2010, which provides a public health perspective on such issues.)

The OIE's Biological Threat Reduction Strategy includes aims to: 'Maintain the OIE laboratory twinning programme to improve compliance with OIE Intergovernmental Standards, including for biosafety and biosecurity, to 
create a culture of responsible science and good laboratory practice', including through incorporation in graduate training; and

Advocate that fostering altruistic scientific networks at the national, regional and global level is a means of sustaining expertise, and preventing scientists from contributing to bioweapons development, by encouraging a culture of responsible and transparent science. (OIE 2015: 1)

\section{Conclusion: shared and reciprocal responsibilities in the biosecurity context}

These recent international efforts to respond to the tension between scientific freedoms and responsibilities in the biosecurity context are positive steps towards raising scientific and policy awareness of the issues. However, recent cases such as the H5N1 mammalian transmissibility studies, have highlighted significant policy gaps at a national and international level, and indicate that awareness raising work and science-policy engagement on the development and implementation of biosecurity measures, need substantial further work.

While some of these efforts will necessarily involve consideration and action by individual scientists, with strong institutional support, it is important to recognise that addressing biosecurity issues relating to research, is not a responsibility of the scientific community alone. It can be framed within the reciprocal relationship of science and society outlined above, as a shared responsibility - particularly, within the context of this chapter - of the scientific community and international policymakers in relation to the development and implementation of biosecurity initiatives. Such initiatives are likely to entail some constraints being placed on scientific freedoms by policymakers on security grounds.

The science-society relationship in this area is mediated by other actors, who also have important roles to play in the development of appropriate policy, including research institutions, scientific academies, funders and publishers (United Nations 2013; German Ethics Council 2014: 52). Responsibilities shared by these groups include enabling scientists to make informed judgements on issues with which they may currently be unfamiliar, developing guidance to support decision-making processes at the institutional level, and contributing to effective engagement and deliberation among all groups about the appropriate balance between various values and interests, and robust and broadly acceptable ways of achieving that balance.

Responsible decision-making is required by actors at all levels. Decision-makers will need to make judgements to resolve difficult cases of conflicting values. Scientific freedom, scientific progress, public health, safety and security are all important values and none should be given absolute priority over the others.

(WHO 2010: 28) 
Policymakers' freedom of action also faces various constraints, including lack of knowledge, expertise and evidence. They therefore need, and policy will benefit from, appropriate and effective input from experts, including better information about scientific and technological advances, the impact these can have on the operation of international rules, and the impact that such rules can have on scientific practice (Selgelid 2009). In the biosecurity area the expertise needed will include science, security, public health and ethics, among other areas; there are established methods and processes for drawing in expertise to international policy processes, but these need adequate and sustainable support (Rhodes 2014).

In turn, the scientific community needs to be better informed about the biosecurity implications of research (WHO 2010: 26), and about international governance and policy processes and the ways in which it can engage with them. This will require ongoing dialogue and improvement of existing mechanisms for scientific review and advice. Notably, improvements to the science and technology review process for the BWC were considered by states parties at the Eighth Review Conference in 2016, but little progress was made.

The expectation of responsibility for the consequences of research is relatively uncontroversial for intended applications and easily foreseeable outcomes, but becomes more difficult when assigning responsibility for use of research by others, in unintended ways. Even where scientists do not accept the argument that awareness of and response to biosecurity concerns is part of their responsibilities, their engagement in such processes is still very important, if only from a self-interested perspective, because otherwise policy will develop and be implemented without appropriate scientific input.

\section{Notes}

1 This is for example discussed in German Ethics Council (2014: 11-14).

2 In relation to research that has relevance for biosecurity, dual use refers to 'research conducted for legitimate purposes that generates knowledge, information, technologies, and/or products that can be utilised for both benevolent and harmful purposes' (NIH 2014).

3 'Gain of function' refers to a much broader set of research than that which raises biosecurity concerns - see NSABB (2016: 5, Box 1).

\section{References}

BBSRC (Biotechnology and Biological Sciences Research Council), MRC (Medical Research Council) and Wellcome Trust (2015), 'Position Statement on dual use research of concern and research misuse', https://wellcome.ac.uk/sites/default/ files/wtp059491.pdf (last accessed 8 October 2016).

DFG [Deutsche Forschungsgemeinschaft] and Leopoldina (2014), Scientific Freedom and Scientific Responsibility: Recommendations for Handling Security-relevant Research, 
www.leopoldina.org/uploads/tx_leopublication/2014_06_DFG-Leopoldina_ Scientific_Freedom_Responsibility_EN.pdf (last accessed 8 October 2016).

Fouchier, R., García-Sastre, A., and Kawaoka, Y. et al. (2013), 'Transmission studies resume for avian flu', Science, 339.6119: 520-1.

Frankel, M. S., and Carlson, R. (2011), 'Reshaping responsible conduct of research', American Association for the Advancement of Science Professional Ethics Review, 24.1, www.aaas.org/sites/default/files/migrate/uploads/Professional-Ethics-ReportDelta.pdf (last accessed 8 October 2016).

German Ethics Council (2014), Biosecurity - Freedom and Responsibility of Research: Opinion, Berlin: Deutscher Ethikrat, www.ethikrat.org/files/opinion-biosecurity.pdf (last accessed 8 October 2016).

Government of Australia (2007), Australia Group, www.australiagroup.net/en/ index.html (last accessed 8 October 2016).

InterAcademy Council (2012), Responsible Conduct in the Global Research Enterprise: A Policy Report, Amsterdam, IAP, www.interacademies.net/ file.aspx?id=19789 (last accessed 8 October 2016).

iSEI [Institute for Science, Ethics and Innovation] (2010), 'Who owns science? The Manchester Manifesto', www.isei.manchester.ac.uk/TheManchesterManifesto.pdf (last accessed 8 October 2016).

National Academies (2009), On Being A Scientist: A Guide to Responsible Conduct in Research, 3rd Edition, Washington, DC: National Academies Press, www.nap.edu/catalog/12192/on-being-a-scientist-a-guide-to-responsible-conduct-in (last accessed 8 October 2016).

National Institutes of Health (2014), Tools for the Identification, Assessment, Management and Responsible Communication of Dual Use Research of Concern: A Companion Guide to United States Government Policies for Oversight of Life Sciences Dual Use Research of Concern, www.phe.gov/s3/dualuse/Documents/ durc-companion-guide.pdf (last accessed 8 October 2016).

National Research Council of the National Academies (2004), Biotechnology Research in an Age of Terrorism, Washington, DC: National Academies Press, www.nap.edu/catalog/10827/biotechnology-research-in-an-age-of-terrorism (last accessed 8 October 2016).

NSABB [National Science Advisory Board for Biosecurity] (2012), Findings and Recommendations: March 29-30, 2012, http://osp.od.nih.gov/sites/default/files/ resources/03302012_NSABB_Recommendations_1.pdf (last accessed 8 October 2016).

NSABB [National Science Advisory Board for Biosecurity] (2016), Recommendations for the Evaluation and Oversight of Proposed Gain of Function Research, http:// osp.od.nih.gov/sites/default/files/resources/NSABB_Final_Report_ Recommendations_Evaluation_Oversight_Proposed_Gain_of_Function_ Research.pdf (last accessed 8 October 2016).

NSABB [National Science Advisory Board for Biosecurity] (n.d.), 'National Science Advisory Board for Biosecurity: frequently asked questions', http://osp.od.nih.gov/ office-biotechnology-activities/biosecurity/nsabb/faq (last accessed 8 October 2016).

OIE [World Animal Health Organization] (2015) Biological Threat Reduction Strategy: Strengthening Global Biological Security, Paris, www.oie.int/fileadmin/ Home/docs/pdf/EN_FINAL_Biothreat_Reduction_Strategy_OCT2015.pdf (last accessed 8 October 2016). 
Rhodes, C. (2014), 'BTWC: learning from alternative models of science and technology review', Policy Paper 7 for the Biochemical Security 2030 Project, http:// biochemsec2030.org/policy-outputs (last accessed 8 October 2016).

Rhodes, C., and Sulston, J. (2010), 'Scientific responsibility and development', European Journal of Development Research, 22.1: 3-9.

Royal Netherlands Academy of Arts and Sciences [KNAW] Biosecurity Committee (2013), Advisory Report - Improving Biosecurity: Assessment of Dual-Use Research, Amsterdam: KNAW, www.knaw.nl/en/news/publications/improvingbiosecurity (last accessed 8 October 2016).

Royal Society (2012), Science as an Open Enterprise: The Royal Society Science Policy Centre Report 02/12, London, https://royalsociety.org/ /media/policy/ projects/sape/2012-06-20-saoe.pdf (last accessed 8 October 2016).

Selgelid, M. (2009), 'Governance of dual-use research: an ethical dilemma', WHO Bulletin, 87.9: 720-3, www.who.int/bulletin/volumes/87/9/08-051383/en (last accessed 8 October 2016).

United Nations (2012), Final Document of the Seventh Review Conference, w w w. unog.ch/80256EDD006 B 8954 / ( h t t p A s s e t s) /3E2A1AA4CF86184BC1257D960032AA4E/\$file/BWC_CONF.VII_07+(E).pdf (last accessed 8 October 2016).

United Nations (2013), BWC/MSP/2013/WP.10, 'Addressing modern threats in the Biological Weapons Convention: a food for thought paper, submitted by Australia, Canada, Chile, Colombia, Czech Republic, Finland, Ghana, Lithuania, the Netherlands, Nigeria, Republic of Korea and Sweden, https://documents-ddsny.un.org/doc/UNDOC/GEN/G13/645/78/PDF/G1364578.pdf?OpenElement (last accessed 8 October 2016).

United Nations 1540 Committee (n.d.), 'Factsheet', www.un.org/en/sc/1540/1540fact-sheet.shtml (last accessed 8 October 2016).

United Nations Convention on the Prohibition of the Development, Production and Stockpiling of Bacteriological (Biological) and Toxin Weapons and on their Destruction (1972), www.unog.ch/80256EDD006B8954/(httpAssets)/ C4048678A93B6934C1257188004848D0/\$file/BWC-text-English.pdf (last accessed 8 October 2016).

US Department of Health and Human Services (2016), National Science Advisory Board for Biosecurity Charter, http://osp.od.nih.gov/sites/default/files/NSABB_ Charter_2016.pdf (last accessed 8 October 2016).

US Department of Health and Human Services, National Institutes of Health (2013), 'Recombinant DNA research: actions under the NIH guidelines for research involving recombinant DNA molecules', Federal Register, 78.35: 12074-82, http://osp.od.nih.gov/sites/default/files/resources/FR\%202_21_2013_78_ FR_12074.pdf (last accessed 8 October 2016).

US Government (2012), Policy for the Oversight of Dual Use Research of Concern, http://osp.od.nih.gov/sites/default/files/resources/United_States_Government_ Policy_for_Oversight_of_DURC_FINAL_version_032812_1.pdf (last accessed 8 October 2016).

US Government (2014), Deliberative Process and Research Funding Pause on Selected Gain-of-function Research Involving Influenza, MERS and SARS Viruses, www.phe.gov/s3/dualuse/documents/gain-of-function.pdf (last accessed 8 October 2016).

Verhoog, H. (1981), 'The responsibilities of scientists', Minerva, 19.4: 582-604. 
WHO (2006), Biorisk Management: Laboratory Biosecurity Guidance, Geneva: World Health Organization, www.who.int/csr/resources/publications/biosafety/ WHO_CDS_EPR_2006_6.pdf (last accessed 8 October 2016).

WHO (2010), Responsible Life Sciences Research for Global Health Security: A Guidance Document, Geneva: World Health Organization, www.who.int/csr/ resources/publications/HSE_GAR_BDP_2010_2/en (last accessed 8 October 2016).

WHO (2012), Report on Technical Consultation on H5N1 Research Issues, Geneva: World Health Organization, www.who.int/influenza/human_animal_interface/ mtg_report_h5n1.pdf.ua=1 (last accessed 8 October 2016).

WHO (2013), Report of the Informal Consultation on Dual Use Research of Concern, Geneva: World Health Organization, www.who.int/csr/durc/durc feb2013_full_mtg_report.pdf (last accessed 21 June 2017). 